\title{
Büyük Doğal Sayıları Okuma ve Yazmada Öğrencilerin Yaşadığı Güçlükler
}

\section{Mustafa ALBAYRAK*, Nurullah YAZICI ${ }^{* *}$, Mertkan ŞİMŞEK ${ }^{* * *}$}

Öz: Bu araştırma ortaokul ikinci sınıf öğrencilerinin milyona kadar ve milyondan daha büyük doğal sayıları okuyup-yazmada yaşadıkları güçlükleri belirlemek amacıyla yapılmıştır. Nitel araştırma yöntemlerinden durum çalışması deseninin kullanıldığı araştırmanın katılımcılarını Doğu Anadolu Bölgesindeki bir okulda öğrenim görmekte olan 55 öğrenci oluşturmaktadır. Veri toplama amacıyla araştırmacılar tarafından geliştirilen 10 tane açık uçlu sorudan oluşan SOYF (Sayıları Okuma Yazma Formu) kullanılmıştır. Araştırmada elde edilen verilerin analizinde içerik analizinden faydalanılmıştır. Araştırma sonucunda öğrencilerin sayıları okuyup yazmada, rakamları gruplandırmada ve rakamları gruplandırdıktan sonra grupları basamak değerlerine göre yazmada eksikliklerinin olduğu tespit edilmiştir. Ayrıca sayıların gruplandırılma aşamasında " 0 ” rakamının yanlış yerde eksik ya da fazladan kullanımına bağlı olarak sayıların okunuşunda eksikliklerin olduğu belirlenmiştir. Araştırma bulguları doğrultusunda sayı öğretiminde basamak değeri ve gruplandırma üzerine etkinliklerin yapılması gerektiği ve "0" rakamının sayı içerisinde kullanımına ilişkin öğrenci eksiklikleri bilinerek, sayı öğretiminde "0" rakamının öğretimine ilişkin zengin örneklere yer verilmesinin gerekli olduğu önerilmiştir.

Anahtar Kelimeler: Sayılar, basamak kavramı, onluk sistem, sayıları gruplandırma, öğrenci zorlukları.

\section{Difficulties of Students in Reading and Writing Big Natural Numbers}

Abstract: This research was conducted in order to determine the difficulties experienced by the 6th grade students in primary education in reading and writing natural numbers up to a billion and the higher ones. The study group using the case study design, one of the qualitative

\footnotetext{
* Doç. Dr. Mustafa ALBAYRAK, Atatürk Üniversitesi, K. K. Eğitim Fakültesi, İlköğretim Matematik Öğretmenliği Bölümü, Erzurum/TÜRKIYE. e-mail: albayrak@atauni.edu.tr ORCID: 0000-0002-3788-5717

** Dr. Nurullah YAZICI, Karamanoğlu Mehmetbey Üniversitesi, Eğitim Fakültesi, İlköğretim Matematik Öğretmenliği Bölümü, Karaman/TÜRKIYYE. e-mail: nyazici@kmu.edu.tr ORCID: 0000-0002-5594-8347

**** Dr. Mertkan ŞİMŞEK, Ağrı İbrahim Çeçen Üniversitesi, Eğitim Fakültesi, İlköğretim Matematik Öğretmenliği Bölümü, Ağrı/TÜRKIYYE. e-mail: mertkans@gmail.com ORCID: 0000-0002-5613-0299
} 
research methods, is composed of 55 students who are studying in a school in Eastern Anatolia Region. The NRWF (Numbers Reading and Writing Form), which is composed of 10 openended questions developed by researchers for data collection was used. Content analysis and descriptive statistics were used in the analysis of the data obtained in the research. As a result of the research, it was determined that the students had deficiencies in reading and writing the numbers, grouping the figures and grouping the figures according to their step value after grouping the figures. It was also determined that the numbers are missing in reading the numbers due to underuse or overuse of the digit " 0 " in the wrong place during the grouping phase. In the direction of the research findings it has been proposed that activities about the digit value and grouping concepts in numerical teaching should be conducted and knowing student deficiencies related to the use of the number " 0 ", rich examples should be carried out in teaching “ 0 ”.

Keywords: Numbers, step value concept, decimal system, grouping numbers, student difficulties.

\section{Giriş}

İnsanoğlunun içinde yaşadığı dünyayı anlama algısının ve devamlı bir şeyleri mukayese etme gereksiniminin bir ürünü olan sayı kavramının oluşumunun insanlık tarihi kadar eski olduğu bilinmektedir (Argün, Arıkan, Bulut ve Halıcıŏ̆lu, 2014; Yıldırım, 2010). İlk çağlarda insanların sayma işlemi için küçük taşlar kullanarak birebir eşleme, kil tabletlere çizik atma veya ip üstüne düğüm atma gibi değişik sayma yöntemleri kullandıklarına yapılan çalışmalarda rastlanılmaktadır (Argün ve diğ. 2014; Gözkan, 2016). Bu anlamda doğada bulunan varlık, eşya ve nesneleri ifade etmede sayma ve sayı kavramlarının kullanılmasının insanoğluna kolaylık sağlayacağı yadsınamaz bir gerçektir. Doğadaki nesnelerin rakam ve sayılar kullanılarak ifade edilişi matematiksel ifade olarak isimlendirilebilir. Ayrıca bireylerin matematiksel algılarının ilk basamağının sayı hissinin gelişimi yani sayma ve sayı kavramını kullanabilme yetisinin olduğu bilinmektedir (Olkun, Fidan ve Özer, 2013).

Matematiğin sayıları kullanarak hesaplama, akıl yürütme ve düşünebilme boyutu düşünüldüğünde sayma ve sayı kavramının özellikle de sayıları anlamlandırabilmenin (herhangi bir sayıyı okuyabilme ya da sözel olarak ifade edebilme) önemi daha kolay anlaşılabilir (Umay, 1996). Bu nedenle öğretim programında okul öncesi eğitimden itibaren matematik derslerinde öğrencilere kazandırılacak ilk beceriler arasında sayma ve sayı 
kavramlarının öğretimi geniş yer almaktadır (Milli Eğitim Bakanlığı [MEB], 2018). Bununla birlikte gerek matematikte gerekse günlük yaşantı içerisinde sayma ve sayı kavramına yönelik yeterince beceri edinemeyen öğrencilerde ilerleyen dönemlerde matematiğe karşı olumsuz bir tutum gelişebilme ihtimali de vardır (Başar, Ünal ve Yalçın, 2002).

Sayma, doğada bulunan sayılabilen nesneler üzerinde yürütülen bir işlem; sayı ise bu işlemin sonucunun ifadesi olarak tanımlanabilir. Diğer bir ifadeyle sayma süreç, sayı ise sonuçtur (Albayrak, 2010). Argün ve diğerlerine (2014) göre sayı kavramı "sayma, etiketleme, sıralama, kodlama, ölçme vb. eylemler için kullanılan matematiksel nesneler" olarak ifade edilmiştir. Fayol ve Seron (2005) sayı kavramını sözlü sayma veya yazılı sembollerden soyutlanmış bir iç temsil olarak yorumlamışlardır. Dolayısıyla insanoğlunun nesneleri karşılaştırabilme, nesnelerin miktarını ölçebilme ya da nesnelerin özelliklerini sayabilme gibi birbiriyle olan iletişiminde sayıları kullandığı veya sayma işlemi yaptığı aşikardır. Bu anlamda sayma ve sayı kavramının iletişim boyutunda da önemli kavramlar olduğu görülmektedir (Cawley ve Reines, 1996).

Günümüzde varlık, eşya, nesnelerin ifade edilmesinde onluk sayma sistemi yaygın olarak kullanılmaktadır. Onluk sayı sisteminin öğrencilere açıklanmasında, her onluk grup elde edildiğinde sayının adının değişmesi (bir tane on, on; iki tane on veya yirmi; üç tane on veya otuz..., on tane on veya yüz, on tane yüz veya bin...) gerekliliğine dikkat edilmelidir (Albayrak, 2010). Ayrıca sayıları ifade etmede on tane rakam $(0,1,2, \ldots .9)$ kullanıldığı için de onluk sayı sistemi olarak isimlendirildiği (Dinç-Artut ve Tarım, 2006) vurgulanmalıdır.

Onluk sayı sisteminde ifade edilen her bir sayının açılımı 10'nun kuvvetleri olarak yazılabilir (Hacısalihoğlu, Hacıyev ve Kalantarov, 2000). Örneğin, 548 sayısı denilince, 5 tane $100=5 \times 10^{2}$ den, 4 tane $10=4 \times 10^{1}$ den ve 8 tane $1=8 \times 10^{0}$ ' dan oluşan ve $10^{\prime}$ nun kuvvetleri olarak yazılabilen çokluk akla gelmektedir (Danışman, 2013).

Eskiden kullanılan Roma sayma sisteminde basamak değeri özelliği yoktur. Bununla birlikte Roma rakamlarında sıfır da olmadığından dört işlem yapmak oldukça zordur (Milli Eğitim Bakanlığı [MEB], 2013a). Onluk sayı sisteminde basamak esasına dayalı oluşum ve de herhangi bir sayıyı ifade edebilmek için "rakam" olarak tanımlanan 10 tane sembolün $(0,1,2, \ldots .9)$ kullanılması, onluk sayı sistemini kullanılabilir ve güçlü kılan özelliklerdir (Baturo, 1997). Basamak değeri kavramı, rakamların sayı içerisinde bulundukları yere göre 
almış oldukları değer olarak tanımlanır (Arslan ve Ubuz, 2014). Onluk sayı sisteminin bu özelliğinden dolayı rakamların birden fazla kullanılabilmesi mümkün olabilmektedir.

Basamak kavramı, zihinden hesap yapma, doğal sayıların okunması ve yazılması gibi birçok aritmetik işlem için gerekli olduğu kadar başta cebir olmak üzere matematiğin diğer dalları için de önem arz eden soyut bir kavramdır (Arslan ve Ubuz, 2014; Dinç Artut ve Tarım, 2006). Bununla birlikte basamak değeri kavramı, matematikle ilişkili olan toplama, çıkarma, çarpma gibi temel aritmetik işlemler, onluk veya yüzlük bozmayı gerektiren işlemler ya da ondalık kesirlerle yapılan işlemler gibi birçok becerilerin öğrencilere kazandırılması noktasında temel bir kavramdır (Van de Walle, Karp, Bay-Williams, Wray ve Brown, 2007).

İki basamaklı sayılardan itibaren sayı öğretiminde basamak kavramına sürekli vurgu (Kaç onluk?, Kaç birlik?, Kaç yüzlük?, Kaç onluk?, Kaç birlik?, Kaç binlik?...) yapılır (Albayrak, 2010). Bu kavram, genel manada basit bir kavram olarak görülmesine rağmen, yapılan araştırmalar sonucunda, öğrencilerin ilk ve ortaokul dönemlerinde basamak değerini tam olarak kavrayamadıkları için temel aritmetik işlemlerde bile sıkıntı yaşadıkları belirlenmiştir (Albayrak, İpek ve Işık, 2006; Chambris, 2008; Dinç Artut ve Tarım, 2006; Garlikov 2000; Thomas, 1996; Thomas, 2000; Thompson ve Bramald, 2002; Thompson 2003). Ayrıca Vareles ve Becker (1997), basamak değeri hakkında yeterli ön bilgiye sahip olan öğrencilerle yaptığı çalışmada öğrencilere bir ön test uygulamış ve bu testin sonucunda öğrencilerin \%96,5'nin basamak değeri konusunda sıkıntılar yaşadıklarını ve basamak değerini sayı değeri kavramı ile karıştırdıklarını ifade etmişlerdir.

Basamak değeri kavramının bir sonucu olarak, herhangi bir sayının içerisinde yer alan bir rakamın -eğer varsa- sağındaki veya solundaki rakamlarla, basamak değeri cinsinden 10'un kuvvetleri şeklinde azalan veya artan bir ilişki mevcuttur. Daha genel bir ifadeyle, sayıda yer alan bir rakam bir basamak sola geçerse basamak değeri 10 kat artar ya da sayıda yer alan bir rakam bir basamak sağa geçerse basamak değeri 10 kat azalır. Şekil 1'de onluk sayı sistemindeki bu ilişki gösterilmiştir (Arslan ve Ubuz, 2014).

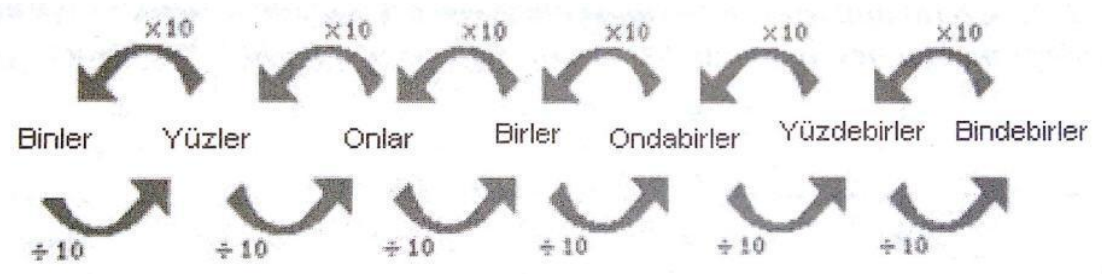


Öğrencilerin çoğunluğu, Şekil 1'de verilen basamaklar arasındaki ilişkiyi kurmakta yani basamak ve sayı değerlerini ayırt etmekte ve sayıları basamak değerlerine göre gruplandırmada güçlükler yaşamaktadırlar. $\mathrm{Bu}$ durumun sonucu olarak da öğrenciler kendilerine sözel olarak söylenen (veya yazılan) bir sayıyı, matematiksel olarak rakamlarla ifade etmekte güçlükler yaşamaktadırlar. Sözel olarak söylenen (veya yazılan) bir sayıyı öğrencilerin matematiksel olarak ifade ederken yaşadığı güçlüklerin ne denli fazla olduğu Thomas'ın (1996), 6. sınıfa gelmiş öğrencilerin \%40’nın hâlâ “on binlerin” yerini söyleyemediklerini ortaya koyduğu çalışmasında görülmektedir. Yine bu çalışmaya ek olarak, Kamii ve Joseph (1988), iki basamaklı bir sayının onlar basamağındaki rakamın basamak değerini öğrencilere sormuş ve öğrencilerin yarıya yakın kısmının bu soruya doğru olarak cevap veremediklerini belirlemişlerdir. Bu duruma öğrencilerin basamak değeri kavramını tam olarak kavrayamamalarının sebep olduğunu belirtmişlerdir. Son yıllarda yapılan araştırmalar da, bu durumun süregelen bir eksiklik olduğunu ortaya koymaktadır (Dinç Artut ve Tarım, 2013; Can, 2017; Sar1 ve Olkun, 2019).

İlkokul matematik programında öğrencilere, sayılarla ilgili gerçek hayata ve sonraki öğretim yaşantılarına temel oluşturacak bilgi ve beceriler kazandırılacağı için, programda sayı öğretiminin ilkokul birinci sınıftan itibaren başladığı, doğal sayılar ve doğal sayılarla yapılan işlemlere geniş bir şekilde yer verildiği ve ikinci sınıftan itibaren basamak değerinin (birlik, onluk, yüzlük,..) vurgulanmaya başlandığı görülmektedir. (MEB, 2013a; Dinç Artut ve Tarım, 2013). Dolayısıyla basamak değeri ile ilgili etkinlikler yapılarak, basamak değerinin öğretimi ile ilgili önceden belirlenmiş olan hedeflere ulaşılabileceği düşünülmüştür. Belirlenen hedeflere ulaşılabilmesi için de öğretimin her aşamasında sayı ve işlem öğretimi üzerinde önemle durulması gereklidir (Dinç Artut ve Tarım, 2013).

Matematik Programında ortaokul birinci sınıfta sayılar ve işlemler öğrenme alanı başlığı altında doğal sayılarla ilgili üç kazanımın dokuz saatlik bir sürede (en çok dokuz basamaklı doğal sayıların bölüklerini, basamaklarını ve rakamların basamak değerlerini öğretiminin) tamamlanması gerektiği belirtilmiştir (MEB, 2017). Daha büyük doğal sayıların okunup yazılması ile ilgili olarak matematik ders kitaplarındaki yönlendirmeyle (milyonlar bölüğünden sonraki bölüklerin milyar, trilyon, katrilyon, kentrilyon, seksilyon, septrilyon, oktilyon, nonilyon ve desilyon) yetinilmiştir (MEB, 2017). Dolayısıyla matematik öğretim programına göre ortaokul birinci sınıfı bitirmiş ögrencilerin doğal sayıları okuma ve yazma ile 
ilgili bilgileri edinmiş olması beklenmektedir. $\mathrm{Bu}$ bilgiler doğrultusunda öğrencilerin milyondan daha büyük sayıları okuyabilmeleri ve yazabilmeleri ile ilgili durumun belirlenmesi problem durumunu oluşturmaktadır. Günlük yaşantıda, yazılı ve görsel basında çeşitli vesilelerle trilyon, katrilyon ifadelerinin kullanıldığı bilinmektedir. Bu amaçla araştırmanın problemi ortaokul öğrencilerinin doğal sayıları okuyup yazmada güçlükleri var mıdır? şeklinde belirlenmiştir.

Alt problemler:

1- Öğrencilerin rakamla verilen büyük doğal sayıları okumada yaşadıkları güçlükler nelerdir?

2- Öğrencilerin okunuşu verilen büyük doğal sayıları rakamla yazarken yaşadıkları güçlükler nelerdir?

3- Öğrencilerin çözümlenmiş halde verilen büyük doğal sayıları yazarken ve okurken yaşadıkları güçlükler nelerdir?

\section{Yöntem}

\section{Araştırma Deseni}

Ortaokul öğrencilerinin doğal sayıları okuyup-yazmada yaşayabilecekleri güçlüklerin detaylı şekilde incelenerek güçlüklerin tespit edilmesi amacıyla bu araştırma, nitel araştırma yöntemlerinden durum çalışması deseniyle yürütülmüştür. Durum çalışması, belirli bir durumu detaylı incelemeye ve durumu betimlemeye imkân verir (Creswell, 2012). Dolayısıyla bu çalışmada durum çalışması deseni kullanılarak, öğrencilerin doğal sayıları okuyup-yazma durumlarında karşılaştıkları güçlükler detaylı incelemeye tabi tutularak betimlenmiştir.

\section{Katılımcılar}

Araştırmanın katılımcılarını 2016-2017 eğitim-öğretim yılında bir ortaokulun ikinci sınıfının iki şubesinde öğrenim görmekte olan toplam 55 öğrenci oluşturmuştur. Araştırmanın ortaokul ikinci sınıf öğrencileri üzerinde yapılmasının sebebi doğal sayılarla ilgili öğrenme etkinliklerinin ortaokul birinci sınıf sonunda tamamlanmış olmasıdır. 


\section{Veri Toplama Araçları}

Araştırmada ilk olarak doğal sayıların okunup yazılmasına ilişkin ilkokul ve ortaokul matematik müfredatı (MEB, 2017) ve ders kitapları incelenmiştir. Ardından ortaokul öğrencilerinin doğal sayıları okuyup yazmada yaşadıkları güçlükleri belirleyebilmek amacıyla araştırmacılar tarafından 10 tane açık uçlu sorudan oluşan SOYF [ Sayıları Okuma Yazma Formu] geliştirilmiştir. SOYF'da rakamla ifade edilmiş sayıların yazıyla ifade edilmesini isteyen, yazıyla verilmiş olan sayıların rakamla yazılışının verilmesini isteyen ve çözümlenmiş haldeki sayıların yazılışını isteyen sorular bulunmaktadır. Hazırlanan form öncelikle ilköğretim matematik eğitimi alanında uzman üç kişi tarafından incelenmiş ve uzman dönütleri bağlamında gerekli düzenlemeler yapılmıştır. Formun son hali oluşturulmadan önce bir ilkokulda 65 öğrenciye SOYF pilot çalışma olarak uygulanmıştır. Pilot uygulamada öncelikle soruların okunması ve anlaşılması ile ilgili durumlar incelenmiştir. Pilot uygulama sonunda hazırlanan sorularda ortaya çıkan eksiklikler, hatalı ya da yanlış anlaşılmaya mahal oluşturabilecek durumlar gözden geçirilerek formun son hali oluşturulmuştur.

\section{Verilerin Analizi}

Araştırmada elde edilen verilerin analizinde içerik analizi tekniklerinden faydalanılmıştır. Araştırma verilerinin tablolara aktarılmasında verilerin anlaşılabilirliğini artırmak için betimsel istatistikler kullanılmıştır (Yıldırım ve Şimşek, 2004). İçerik analizi, ulaşılan verilerin temel öğelerini belli kategoriler altında tasnif etmek ve yorumlamak amaciyla kullanılan objektif ve sistematik bir tekniktir (Robert ve Bouillaget, 1997). Araştırmanın amacı ve hedefleri doğrultusunda ilk olarak çalışma kapsamındaki öğrencilerden elde edilen veriler kodlanmıştır. Kodlar öğrencilerin okuma ve yazma ile ilgili doğru ve yanlışları ile bu yanlışların çeşitleri şeklinde oluşturulmuştur. Veriler kodlandıktan sonra, araştırmacılar tarafından kodların tutarlılığı "Görüş Birliği" veya "Görüş Ayrılığı" olan maddeler işaretlenerek belirlenmiştir. Öğrencilerin sorulara yazmış olduğu cevaplara göre, araştırmacıların aynı kodu kullandığı durumlar "Görüş Birliği”; araştırmacıların aynı kodu kullanmadığı durumlar ise "Görüş Ayrılığı" olarak kabul edilmiştir. Miles ve Huberman'ın (1994) ortaya koyduğu “Güvenirlik = Görüş Birliği / (Görüş Birliği + Görüş Ayrılığı)” formül kullanılarak araştırmanın güvenirliği \%81 bulunmuştur. Miles ve Huberman (1994), bir araştırmanın güvenilir kabul edilebilmesi için, güvenirlik hesaplarının \%70'in üzerinde çıkmasının yeterli olacağını belirttikleri için yapılan araştırma güvenilir olarak kabul edilmiştir. 
Ayrıca araştırmada sunulan bulgularda öğrenci cevaplarının fotoğrafları verilmiş ve böylece araştırmanın geçerlik ve güvenilirliğinin artırılması sağlanmıştır.

\section{Bulgular}

Bu bölüme araştırma problemleri doğrultusunda elde edilen bulgular yazılmıştır.

\section{Rakamla ifade edilen sayıları okuyabilmeye ilişkin bulgular}

SOYF formunda öğrencilere rakam ile yazılmış dört sayı yöneltilmiş ve öğrencilerden rakamla ifade edilen bu sayıların okunuşunu yazmaları istenmiştir. Tablo 1'de, öğrencilerin rakamla yazılmış olan sayıların okunuşunu yazabilmelerine ilişkin bulgular yazılmıştır.

Tablo 1. Verilen ifadeleri okuyabilme

\begin{tabular}{|c|c|c|}
\hline & \multicolumn{2}{|c|}{ *Yazılan cevap sayısı } \\
\hline & $\%$ & f \\
\hline Doğru okuyabilme & 53 & 117 \\
\hline Yanlış okuma & 47 & 103 \\
\hline \multicolumn{3}{|c|}{$\begin{array}{l}\text { *Çalışmaya katılan öğrencilerin yazdıkları cevap } \\
\text { sayısını (220) ifade etmektedir. \% ve f değerleri toplam } \\
\text { cevap sayısı üzerinden hesaplanmıştır. }\end{array}$} \\
\hline
\end{tabular}

Tablo 1 incelendiğinde, öğrencilerin cevaplarının yaklaşık yarısının ( $f=103)$ yanlış olduğu görülmektedir. Bu durum öğrencilerin rakamla ifade edilen büyük sayıları okumada eksikliklerinin olduğunu göstermektedir. Bununla birlikte rakamla ifade edilen sayıları doğru okuyabilme ve yanlış okuyabilme oranlarının birbirlerine çok yakın olduğu da dikkate değerdir.

Rakamla ifade edilen sayıların okunuşunu yanlış olarak yazan öğrencilerin cevapları içerik analizine tabi tutulduğunda öğrencilerin rakamla ifade edilen sayıları okuyabilmede yaşadıkları güçlüklere ilişkin Tablo 2'deki bulgulara ulaşılmıştır.

Tablo 2. Öğrencilerin rakamla ifade edilen sayıları okuyabilmeye ilişkin yaşadıkları güçlükler

\begin{tabular}{llc}
\hline \multirow{2}{*}{ Öğrencilerin Yaşadıkları Güçlükler } & \multicolumn{2}{c}{$*$ Öğrenci Sayısı } \\
\cline { 2 - 3 } & $\mathbf{\%}$ & $\mathbf{f}$ \\
\hline Basamak değerlerini sağdan sola doğru ayıramama & 18 & 10 \\
\hline
\end{tabular}


(Bölük kavramı)

\begin{tabular}{llll}
\hline Altı basamaktan sonrasını okuyamama & 32 & 18 \\
\hline Rakamları gruplandırdıktan & sonra & grupları & \\
basamak değerlerine (yüzler, binler & vs. $\quad$ ) göre 27 & 15 \\
yazamama & & \\
\hline *Çalışmaya katılan toplam öğrenci & (55) sayısını ifade etmektedir. \% ve f \\
değerleri toplam öğrenci sayısı üzerinden hesaplanmıştır.
\end{tabular}

Tablo 2'de ifade edildiği gibi, öğrencilerin basamak değerlerini soldan sağa doğru ayırmada (10 öğrenci), altı basamaktan sonrasını okumada (18 öğrenci) ve rakamları gruplandırdıktan sonra grupları basamak değerlerine göre yazmada (15 öğrenci) güçlükler yaşadıkları tespit edilmiştir.

$5.6,347758698$ \& 3 sayısının okunuşunu alttaki kutunun içine yazınız

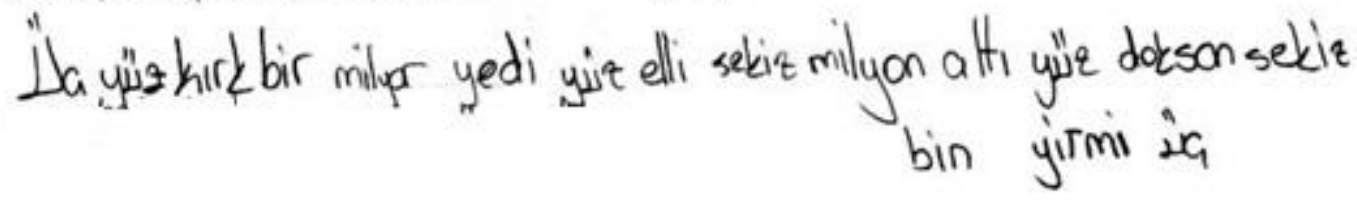

Şekil 2. Ö 15 'in sayının yazılışında basamakları soldan başlayarak gruplandırmasına yönelik örnek

Şekil 2'de verilen örnek incelendiğinde Ö̈ 15 'in sayıların basamak değeriyle ilgili yanlış başlangıç yaptığı görülmektedir. "Otuzdört milyar" diye başlamaları gereken okumaya “üçyüzkırkbir milyar” şeklinde başlaması bunun göstergesidir. Öğrencilerin yanlış başlangıç yapmalarının temelinde öğrencilerin verilen sayının basamaklarını üçer üçer gruplandırmaya soldan başlamış olmaları şeklinde öğrenme güçlüklerinin olduğu söylenebilir.

$$
\begin{aligned}
& \text { 5.7! 800003001005 sayısınเn okunuşunu a'ttaki kutunun içine yazuna } \\
& \text { Sek1240 } 20+42 m / 140061 n 6 e s
\end{aligned}
$$

Şekil 3. Ög'un sayının yazılışında altı basamaktan büyük sayılarda hata yapmasına yönelik örnek

Şekil 3'te Ög'un birler ve binler bölügüne ait sayıları doğru okurken daha sonraki bölükleri doğru okuyamadığg görülmektedir. Bu durum bazı öğrencilerin milyona kadar zorluk yaşamayıp, milyondan sonra zorluk yaşadıklarını göstermektedir. 


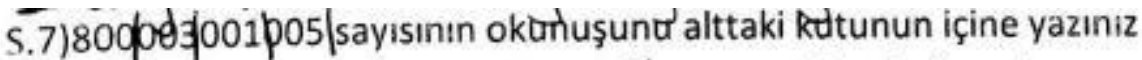 Selic ÿz milyor üa milyon bir bin bes?}

Şekil 4.Ö ${ }_{17}$ 'un sayının yazılışında altı basamaktan büyük sayılarda hata yapmasına yönelik örnek

Şekil 4'te Ö 17 'nin gruplamayı doğru yapmış olmasına rağmen okunuşunu doğru ifade edemediği görülmektedir. "sekizyüz milyar üç milyar bir bin beş" okunuşunda "bir bin" ifadesinin sadece "bin" olarak okunması gerekmektedir. Bu zorluğun sebebi dili doğru kullanabilme eksikliği olabilir.

\section{Okunuşu sözel olarak ifade edilen sayıları rakamla yazabilmeye ilişkin bulgular}

SOYF'nda öğrencilere okunuşuyla yazılmış biçimde dört sayı yöneltilmiş ve öğrencilerden okunuşuyla ifade edilen bu sayıları rakamla yazmaları istenmiştir. Tablo 3'de, öğrencilerin sözel olarak ifade edilen sayıları rakamla ifade edebilmesine ilişkin bulgular yazılmıştır.

Tablo 3. Okunuşu yazılan sayıları rakamla yazabilme

\begin{tabular}{lcc}
\hline & \multicolumn{2}{c}{ *Yazılan cevap sayısı } \\
\cline { 2 - 3 } & $\%$ & f \\
\hline Doğru okuyabilme & 57 & 125 \\
\hline Yanlış okuma & 43 & 95 \\
\hline *Çalışmaya katılan & öğrencilerin & yazdıkları cevap \\
$\begin{array}{l}\text { sayısını (220) ifade etmektedir. \% ve f değerleri toplam } \\
\text { cevap sayısı üzerinden hesaplanmıştır. }\end{array}$ \\
\hline
\end{tabular}

Tablo 3 incelendiğinde, öğrenci cevaplarının yarısından fazlasında ( $\mathrm{f}=125)$ okunuşu yazılmış olan sayıları doğru biçimde rakamla yazabildikleri bulgusu görülmektedir. Bununla birlikte, okunuşu yazılan sayıları rakamla yazabilme oranlarının da birbirlerine çok yakın olduğu söylenebilir.

Okunuşu yazılan sayıları rakamla ifade ederken yanlış olarak yazan öğrencilerin cevapları doğru olarak yazabilen öğrencilerle birlikte içerik analizine tabi tutulduğunda, 
öğrencilerin okunuşu yazılan sayıları rakamla yazabilmeye ilişkin yaşadıkları güçlükler Tablo 4'de yazılmıştır.

Tablo 4. Öğrencilerin okunuşu yazılan sayıları rakamla yazabilmeye ilişkin yaşadıkları güçlükler

\begin{tabular}{|c|c|c|}
\hline \multirow[b]{2}{*}{ Öğrencilerin Yaşadıkları Güçlükler } & \multicolumn{2}{|c|}{ *Öğgrenci Sayısı } \\
\hline & $\%$ & $\mathbf{f}$ \\
\hline $\begin{array}{l}6 \text { basamaktan daha büyük sayıları rakamla ifade } \\
\text { edememe }\end{array}$ & 32 & 18 \\
\hline $\begin{array}{l}\text { Rakamları basamak değerlerine göre } \\
\text { gruplandırmada "0" rakamını dikkate almama }\end{array}$ & 29 & 16 \\
\hline $\begin{array}{l}\text { Sıfırın yanlış yerde eksik ya da fazladan } \\
\text { kullanımı }\end{array}$ & 21 & 12 \\
\hline $\begin{array}{l}\text { *Çalışmaya katılan toplam öğrenci (55) sayısını } \\
\text { değerleri toplam öğrenci sayısı üzerinden hesapla }\end{array}$ & fad & \\
\hline
\end{tabular}

Tablo 4'de, öğrencilerin 6 basamaktan daha büyük sayıları rakamla ifade etmeye (18 öğrenci), rakamları basamak değerlerine göre gruplandırma esnasında " 0 ” rakamını dikkate almamaya (16 öğrenci) ve sıfırın yanlış yerde eksik ya da fazladan kullanımına (12 öğrenci) ilişkin güçlükler yaşadıkları tespit edilmiştir.

\section{Sekiz milyon beş bin üç

$$
800,005,003
$$

Şekil 5. Ö 13 'ün sayının rakamla yazılışında altı basamaktan büyük sayılarda hata yapmasına yönelik örnek

Şekil 5'de verilen örnekte Ö̈ 13 'ün altı basamaktan daha fazla basamağı olan sayıları rakamla yazabilmede zorluk yaşadığı görülmektedir. Birler ve binler bölüğünde başarı sağlanmışken sonraki bölüklerde zorluklar ortaya çıkmıştır.

- Ellibır milyar onsekiz bin beş

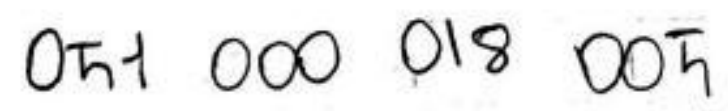

Şekil 6. Ö̈35'in sıfır rakamının yanlış kullanımından dolayı hata yapmasına yönelik örnek 
Şekil 6'da verilen örnekte Ö̈35’in “sıfır” rakamının kullanılacağı basamaklarda yaşadığı zorluk görülmektedir. Şekil 6 incelendiğinde "sıfır" rakamının fazladan yazıldığı (en büyük basamağın solundan itibaren “sıfır” rakamının yazılmasına gerek yoktur”) görülmektedir.

\section{Sekiz milyon beş bin üç}

$$
800,005,003
$$

Şekil 7. Ö 19 'un sıfır rakamının yanlış kullanımından dolayı hata yapmasına yönelik örnek

Şekil 7'de ise Ö̈19'un "sıfır” rakamının basamaklarda sıkça kullanıldı̆̆ı durumda sayının yanlış yazılmasına sebep olduğuna dair örnek görülmektedir. Buna benzer şekilde "sıfır" rakamının yanlış yerde kullanılması veya fazladan/eksik kullanılması da yine rakam ile ifade etmede yanlışlara sebep olmuştur.

Çözümlenmiş olarak ifade edilmiş olan sayıları rakamla yazmaya ve okuma ilişkin

\section{bulgular}

SOYF formunda öğrencilere çözümlenmiş biçimde (hem okunuşuyla çözümlenmiş hem de rakamla çözümlenmiş halde) 2 sayı yöneltilmiş ve öğrencilerden çözümlenmiş olarak ifade edilen bu sayıları hem rakamla ifade etmeleri hem de okunuşunu yazmaları istenmiştir. Tablo 5'de öğrencilerin çözümlenmiş olarak ifade edilmiş olan sayıları okuyabilme ve rakamla yazabilmelerine ilişkin bulgular yazılmıştır.

Tablo 5. Çözümlenmiş olarak verilen sayıları okuyabilme ve rakamla yazabilme

\begin{tabular}{lcc}
\hline \multicolumn{2}{c}{ Rakamla çözümlenmiş olarak verilen sayıları okuyabilme } \\
\hline & \multicolumn{2}{c}{$*$ Öğrenci Sayısı } \\
\cline { 2 - 3 } & $\mathbf{\%}$ & $\mathbf{f}$ \\
\hline Doğru okuyabilme & 55 & 30 \\
\hline Yanlış okuma & 45 & 25 \\
\hline
\end{tabular}

Okunuşuyla çözümlenmiş olarak verilen sayıları rakamla yazabilme

\begin{tabular}{ccc}
\hline \multicolumn{2}{c}{ *Öğrenci Sayısı } \\
\cline { 2 - 3 }$\%$ & f \\
\hline
\end{tabular}




\begin{tabular}{lcc}
\hline Doğru yazabilme & 67 & 37 \\
\hline Yanlış yazma & 33 & 18 \\
\hline *Çalışmaya katılan toplam öğrenci & (55) & sayısını ifade \\
etmektedir. \% ve f değerleri toplam öğrenci sayısı üzerinden \\
hesaplanmıştır.
\end{tabular}

Tablo 5 incelendiğinde, çözümlenmiş olarak ifade edilmiş olan sayıları öğrencilerin yaklaşık yarısı $(\mathrm{f}=25)$ yanlış olarak okumuşken; okunuşuyla çözümlenmiş halde yazılmış olan sayıları yazabilmede öğrencilerin yarıdan fazlası $(\mathrm{f}=37)$ doğru olarak rakamla yazabildiği bulguları ortaya çıkmıştır. Bu bulgu sayıların okunuş şekliyle ifadesi, çözümlenmiş halde ifade edilen sayıları rakamla ifade etmede öğrencilerin daha az güçlük yaşadıkları şeklinde yorumlanabilir.

Çözümlenmiş olarak ifade edilen sayıları okuyabilme ve rakamla yazabilmeye ilişkin öğrencilerin yaşadıkları güçlükler Tablo 6'da yazılmıştır.

Tablo 6. Çözümlenmiş olarak verilen sayıları okuyabilme ve rakamla yazabilmeye ilişkin öğrenci güçlükleri

\begin{tabular}{llc}
\hline \multirow{2}{*}{ Öğrencilerin Yaşadıkları Güçlükler } & \multicolumn{2}{c}{ *Öğrenci Sayısı } \\
\cline { 2 - 3 } & \% & f \\
\hline $\begin{array}{l}\text { Basamak değerine karşılık gelen rakamın yerini } \\
\text { sayının içinde belirleyememe }\end{array}$ & 32 & 18 \\
\hline $\begin{array}{l}\text { Çözümlenmiş olarak verilen altı basamaktan } \\
\text { daha büyük sayıları okuyamama ve yazamama }\end{array}$ & 29 \\
\hline $\begin{array}{l}\text { *Çalışmaya katılan toplam öğrenci (55) sayısını ifade etmektedir. \% ve f } \\
\text { değerleri toplam öğrenci sayısı üzerinden hesaplanmıştır. }\end{array}$ \\
\hline
\end{tabular}

Tablo 6'da görüldüğ̈̈ üzere, öğrencilerin basamak değerine karşılık gelen rakamın yerini sayının içinde belirleyememe (18 öğrenci) ve çözümlenmiş olarak ifade edilen 6 basamaktan daha büyük sayıları okuyamama ve yazamamaya (16 öğrenci) ilişkin güçlükler yaşadıkları tespit edilmiştir. 


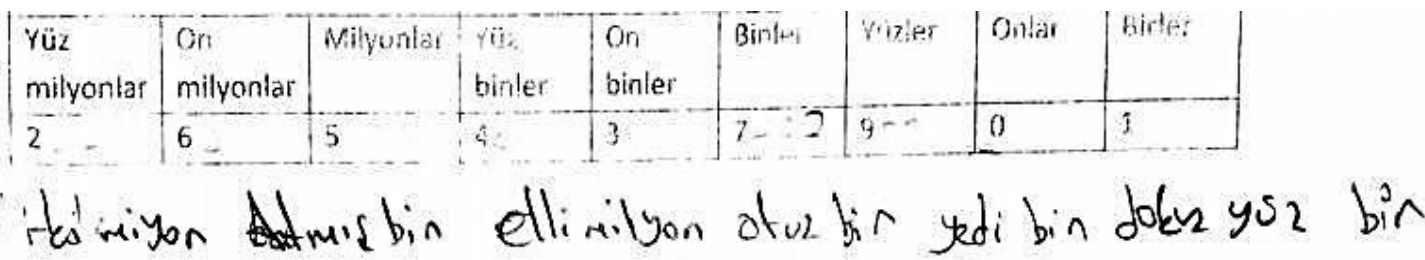

\begin{tabular}{|c|c|c|c|c|c|c|c|c|}
\hline \multicolumn{3}{|c|}{ Milyonlar Bölüğü } & \multicolumn{3}{|c|}{ Binler Bölüğü } & \multicolumn{3}{|c|}{ Birler Bölüğü } \\
\hline $\begin{array}{l}\text { Yüz } \\
\text { milyonlar }\end{array}$ & $\begin{array}{l}\text { On } \\
\text { milyonlar }\end{array}$ & Milyontar & $\begin{array}{l}\text { Yüz } \\
\text { binler }\end{array}$ & $\begin{array}{l}\text { Q7 } \\
\text { binler }\end{array}$ & Binler & Yürler & Onlar & Birler \\
\hline Led bin & AIt! $h$ & Wes, siter & $x_{2}, x=2$ & $a_{1} 6$ & yed b & doleve & Setien & Alti \\
\hline 20000000 & condsobs & $50000 \% 0$ & 402000 & 30500 & 7001 & 900702 & 80 & 6 \\
\hline
\end{tabular}

Çözümlenmiş olarak verilen bir sayıyı rakamla ifade etmek veya okuyabilmek aslında verilen bilgilerin bir bütün olarak ifadesidir. Çünkü basamağın adı, bölüğü vb. bütün bilgiler çözümleme tablosunda verilmiştir. Dolayısıyla karşılaşılan zorluklardan olan basamak değerine karşılık gelen rakamın yerini yanlış ifade etme aslında öğrencilerin basamak değeri kavramını anlamlandıramadıklarını göstermektedir. Ayrıca bu kısımda da altı basamaktan ötesinde öğrencilerin zorluk yaşaması basamak kavramı ile ilgili bilgilerini genelleyememelerinden kaynaklandığının göstergesi olabilir.

\section{Sonuç ve Tartışma}

Araştırma bulguları doğrultusunda araştırma kapsamındaki öğrencilerin sayıları okuyup yazmada eksikliklerinin olduğu tespit edilmiştir. Bu sonuçla araştırma probleminin varlığının bir kez daha teyit edilmiş olduğu söylenebilir. Bununla birlikte yapılan bu araştırmada öğrencilerin sayıları okuyup yazmada yaşadıkları güçlüklerin büyük çoğunluğunun, basamak değeri kavramının yeterince anlaşılmamasının bir sonucu olduğu bulunmuştur. Basamak değeri kavramına ilişkin öğrencilerin altı basamaktan daha büyük sayıları çözümlenmiş olarak ifade edilmiş olsa bile sayıyı okumada ve rakamla ifade etmede güçlükler yaşadığı, basamak değerine karşılık gelen rakamın yerini sayının içinde belirleyemediği ve basamak değerlerini soldan sağa doğru ayıramadıkları sonucuna ulaşılmıştır. Bulunan bu sonuç, Vareles ve Becker'in (1997) basamak değeri kavramına ilişkin araştırma sonuçlarından, öğrencilerin basamak değeri kavramı konusunda sıkıntılar yaşadıklarını ortaya koymalarının yanı sıra öğrencilerin basamak değeri ile sayı değeri kavramını karıştırdıkları sonucu ile benzerdir. Araştırma bulgularına benzer şekilde, yapılan birçok çalışmada (Albayrak, İpek ve Işık, 2006; Chambris, 2008; Dinç Artut ve Tarım, 2006; Garlikov 2000; Thomas, 1996; Thomas, 2000; Thompson ve Bramald, 2002; Thompson 2003) ilköğretim öğrencilerinin basamak değeri kavramında yaşadıkları ve kavrama ilişkin 
eksikliklerin ileriki dönemlerde de aynı şekilde devam ettiği görülmektedir. Ayrıca bu sıkıntıların temel aritmetik işlemlerin yapılmasına yönelik etkisinin olduğunu ifade edilmektedir.

Araştırmada ortaokul öğrencilerinin basamak değeri kavramının temeli olarak kabul edilen "gruplandırma” (birlik, binlik, milyonluk, ...) kavramına ilişkin güçlükler yaşadıkları sonucuna ulaşılmıştır. Ulaşılan bu sonuç, Dinç Artut ve Tarım (2006), Kamii ve Joseph (1988) ile Vareles ve Becker'in (1997) ilköğretim öğrencilerinin basamak değeri kavramına ilişkin yaptıkları çalışmaların sonuçlarıyla paraleldir. Bununla birlikte araştırma bulgularında, bazı öğrencilerin gruplandırma işlemini doğru olarak yaptıktan sonra da gruplandırılmış biçimdeki sayıyı okumada güçlükler yaşadıkları sonucu bulunmuştur. Bu durumun nedenlerinden birisi basamak değeri kavramının soyut bir kavram olması ve ortaokul öğrencilerinin somuttan soyuta geçiş evresinde olmasıdır. Diğger nedeni ise basamak değeri öğretiminin geleneksel öğretim yöntemlerine ek olarak etkinlik temelli öğretimle desteklenmemesidir. Bununla birlikte sayı öğretimine başlandığında, basamak kavramına "Kaç onluk?, Kaç birlik?, Kaç yüzlük?, Kaç onluk?, Kaç birlik?, Kaç binlik?... (Albayrak, 2010)” şeklinde sürekli şekilde vurgu yapılmaması da öğrencilerin gruplandırma işleminde güçlükler yaşamasına sebep olabilecek ilave neden olarak düşünülebilir.

Araştırma sonucunda öğrencilerin rakamları basamak değerlerine göre gruplandırmada “0” rakamını dikkate almadığı veya sıfırı yanlış yerde, eksik ya da fazla olarak kullandığı belirlenmiştir. Bu durum öğrencilerin gruplandırma işlemini yaparken her bir grubun üçerli rakamlardan oluşmasının gerekliliği şeklinde bir yanılgının sonucu olduğu söylenebilir. Yani öğrencilerin -“Sekiz milyon beş bin üç” sayısını rakamla yazarken “008005003” şeklinde yazarak- milyonlar bölüğünde yüz milyonlar ve on milyonlar basamaklarına karşılık gelen rakam olmaması durumunu, milyonlar grubunu bütüncül olarak düşünerek bu boşlukları " 0 ” rakamı ile doldurdukları belirlenmiştir. Bununla birlikte öğrencilerin birçoğu ise, örnek olarak “Sekiz yüz üç milyon on yedi bin kırk dokuz” sayısını rakamla yazarken “0” rakamını eksik ya da fazla olarak kullandıkları belirlenmiştir. Bu durumun nedeni olarak da öğrencilerde "gruplandırma” ve "basamak değeri” kavramına ilişkin yaşanılan güçlüklerin (Can, 2007) yanı sıra öğrencilere farklı etkinlik türleri aracılığıyla sayı kavramının çok boyutlu olarak ele alınmaması (Baroody, 2007) gösterilebilir.

\section{Öneriler}

Araştırma bulguları ve sonuçları doğrultusunda şu önerilere yer verilebilir: 
- Öğrencilere sayı öğretiminde soyut örnekler söyleme yerine günlük hayatla ilişkili olabilen somut ve de farklı etkinlik türleri kullanılmalıdır.

- Sayı öğretiminde basamak değeri ve gruplandırma kavramları üzerinde yeterince durulmalidir.

- “0” rakamının sayı içerisinde kullanımına ilişkin öğrenci eksiklikleri bilinerek, sayı öğretiminde " 0 ” rakamının öğretimine ilişkin zengin örneklere yer verilmelidir.

- Öğrencilerin sayıları okuyup yazabilme ile ilgili eksikliklerinin giderilebilmesi yönünde yapılabilecek etkinlikler (oyunla öğretim) araştırılmalıdır.

\section{Makalenin Bilimdeki Konumu}

Matematik ve Fen Bilimleri Eğitimi/Matematik Eğitimi

\section{Makalenin Bilimdeki Özgünlüğü}

Literatürde sayıların öğretimi ve sayıların öğretiminde öğrencilerin karşılaştıkları zorlukları inceleyen çalışmalar bulunmaktadır. Ancak bu çalışmalar genellikle konu alanını bütün halinde ele almakta veya belirli bir sınıf seviyesinde bu konudaki bütün kazanımları kapsamaktadır. $\mathrm{Bu}$ şekilde yapılmış çalışmalar sayıların okunması ve yazılması ile ilgili derinlemesine bir analiz sunamamaktadır. Bu çalışma sayıların okunması ve yazılması ile ilgili detaylı sonuçlar sunarak bu konuda öğrencilerin karşılaştığı zorlukları belirlemiştir.

\section{Kaynaklar}

Argün, Z., Arıkan, A., Bulut, S., ve Halıcıoğlu, S. (2014). Temel matematik kavramların künyesi. Ankara: Gazi Kitabevi.

Albayrak, M. (2010) İlköğretimde Matematik ve Öğretimi-1, Mega Ofset:Erzurum.

Albayrak, M., İpek, S. ve Işı,, C. (2006). Onluk sayma sisteminin öğretimi, Kazım Karabekir Eğitim Fakültesi Dergisi, 13,199-206.

Arslan, S. ve Ubuz B., (2014). İlköğretimde karşılaşılan matematiksel zorluklar ve çözüm önerileri (4. Bask1), Bingölbali E. ve Özmantar M.F. (Ed.), Sayılarda basamak değeri kavramı ve öğrencilerin yaşadığı zorluklar (s. 97-126)., Ankara: Pegem Akademi.

Baroody, A. J. (2017). The use of concrete experiences in early childhood mathematics instruction. In Advances in child development and behavior (Vol. 53, pp. 43-94). JAI.

Başar, M., Ünal, M., ve Yalçın, M. (2002). İlköğretim kademesiyle başlayan matematik korkusunun nedenleri. V. Ulusal Fen Bilimleri ve Matematik Eğitimi Kongresi, 16-18.

Baturo, Annette R. (1997). The implication of multiplicative structure for students' understanding of decimal-number numeration. In Biddulph, F. and Carr, K., Eds. Proceedings People in Mathematics Education:20th Annual conference of the 
Mathematics Education Research Group of Australasia 1, pages pp. 88-95, Rotorua, New Zealand.

Büyüköztürk, Ş. (2002). Sosyal bilimler için veri analizi el kitabı. Ankara: Pegem Akademi. Can, D. (2017). İlkokul Dördüncü Sınıf Öğrencilerinin Sayı Duyularının Bağlam Temelli ve Bağlam Temelli Olmayan Problem Durumlarında İncelenmesi. Yayınlanmamış Doktora Tezi. Hacettepe Üniversitesi. Eğitim Bilimleri Enstitüsü, Ankara.

Cawley, J. F., ve Reines, R. (1996). Mathematics as communication: Using the interactive unit. Teaching Exceptional Children, 28(2), 29-34.

Chambris, C. (2008). Relations entre les grandeurs et les nombres dans les mathématiques de l'école primaire. Évolution de l'enseignement au cours du 20e siècle. Connaissances des élèves actuels (Doctoral dissertation, Université Paris-Diderot-Paris VII).

Creswell, J. W. (2012). Qualitative inquiry and research design: Choosing among five approaches. Sage publications.

Çangır, M. (2008). Illköğretim Din Kültürü ve Ahlak Bilgisi Derslerinde Eğitsel Oyun Yönteminin Uygulanma Durumu (Tuzla Örneği). Yüksek Lisans Tezi. Yeditepe Üniversitesi, Sosyal Bilimler Enstitüsü: İstanbul.

Danışman, Y. (2013). Tanımları ve tarihsel gelişimleriyle matematiksel kavramlar (1.Baskı), Zembat, İ.Ö, Özmantar, M.F., Bingölbali E, Şandır H.,Delice A. (Ed.), Taban kavramı ve basamak değerleri (s.82-110), Ankara: Pegem Akademi.

Dinç Artut, P. ve Tarım, K. (2006). İlköğretim Öğrencilerinin Basamak Değer Kavramını Anlama Düzeyleri. Ĕgitimde Kuram ve Uygulama, 2(1), 26-36.

Doğanay, G. (2002). Tarih Öğretiminde Oyun. Yayınlanmamış Yüksek Lisans Tezi. Gazi Üniversitesi. Eğitim Bilimleri Enstitüsü, Ankara.

Garlikov, R., (2000). The concept and teaching of place-value. http//www.garlikov.com/placevalue.html. (Erişim tarihi: 02.06.2017)

Hacısalihlioğlu, H.H., Hacıyev, A., ve Kalantarov, V. (2000). Matematik Terimleri Sözlüğü, Ankara: Türk Dil Kurumu.

Kamii, C. ve Joseph, L. (1988). Teaching place value and double-column addition, Arithmetic Teacher, 35(6), 45-52.

Karabacak, N. (1996). Sosyal Bilgiler Dersinde Eğitsel Oyunların Öğrencilerin Erişi Düzeyine Etkisi. Yayınlanmamış Yüksek Lisans Tezi. Hacettepe Üniversitesi Sosyal Bilimler Enstitüsü, Ankara. 
Karasar, N. (2012). Bilimsel araştırma yöntemi: kavramlar, ilkeler, teknikler. Ankara:Nobel Yayın Dă̆ıtım.

MEB (2013a). Illkokul matematik dersi öğretim programı.

http://ttkb.meb.gov.tr/program2.aspx?islem=2\&kno=246 adresinden $\quad 10.03 .2017$ tarihinde alınmıştır.

MEB (2013b). Talim ve Terbiye Kurulu Başkanlı̆̆l ortaokul matematik dersi (5, 6, 7 ve 8. sınıflar) öğretim programı. Ankara: Milli Eğitim Bakanlığı.

MEB (2015). Illköğretim matematik dersi (5. 6. 7. ve 8. sinıflar) öğretim programı, Alınan yer https://ttkb.meb.gov.tr. (15.04.2017 tarihinde alınmıştır)

MEB (2017). Matematik Dersi Öğretim Programı (İlkokul ve Ortaokul 1,2,3,4,5,6,7, ve 8.siniflar) Ankara-2017

Miles, M. B. ve Huberman, A.M. (1994). Qualitative data analysis: an expanded sourcebook. (2nd Edition). California: SAGE Publications.

Olkun, S., Fidan, E., ve Özer, A. B. (2013). 5-7 yaş aralığındaki çocuklarda sayı kavramının gelişimi ve saymanın problem çözmede kullanımı. Eğitim ve Bilim, 38(169).

Robert, A.D. ve Bouillaguet, A. (1997), L'analyse de Contenu, Que Sais-je?, No. 3271, PUF, Paris.

Saracaloğlu, A. S. ve Aldan Karademir, Ç. (2009). Eğitsel oyun temelli fen ve teknoloji öğretiminin öğrenci başarısına etkisi. VIII. Ulusal Sınıf Öğretmenliği Eğitimi Sempozyuтu, Bildiri Kitabı. 21-23 Mayıs 2009. Osmangazi Üniversitesi: Eskişehir. 1098-1107.

Sarı, M. H., \& Olkun, S. (2019). Relationship between place value understanding, arithmetic performance and mathematics achievement in general. İlköğretim Online, 18(2), 953958, [Online]:http://ilkogretim-online.org.tr

Tarım, K. ve Artut, P. D. (2013). Öğretmen adaylarının basamak değeri ve sayma sistemlerini anlama düzeyleri. Ilköğretim Online, 12(3).

Thomas, N. (1996). Understanding the number system. In J.T. Mulligan ve M.C. Mitchelmore (Eds.), Children’s number learning (pp. 89-106). Adelaide: Australian Association of Mathematics Teachers and MERGA.

Thomas, N. (2000). Understanding the number system. Children's number learning: A research monograph of MERGA/AAMT, 75106.

Thompson, I. (2003). Putting place value in its place. Mathematics Teaching, 184, 14-15. 
Thompson, I., and Bramald, R. (2002). An investigation of the relationship between young children's understanding of the concept of place value and their competence at mental addition (Report for the Nuffield Foundation). Newcastle upon Tyne: University of Newcastle upon Tyne.

Umay, A. (1996). Matematik öğretimi ve ölçülmesi. Hacettepe Üniversitesi Ĕ̆itim Fakültesi Dergisi, 12(12).

Van de Walle, J. A., Karp, K. S., Bay-Williams, J. M., Wray, J. A., ve Brown, E. T. (2007). Elementary and middle school mathematics: Teaching developmentally. AddisonWesley Longman

Vareles, M. ve Becker, J., (1997). Children’s developing understanding of place value: semiotic aspect, Cognition and Instruction, 15(2), 265-286.

Yıldırım, A. ve Şimşek, H. (2004). Sosyal bilimlerde nitel araştırma yöntemleri. (2. Baskı). Ankara: Seçkin Yayıncılık.

Yıldırım, C. (2010). Matematiksel düşünme. Remzi Kitabevi. 
YYÜ Eğitim Fakültesi Dergisi (YYU Journal of Education Faculty), 2019; 16(1):1419-1441, http://efdergi.yyu.edu.tr

\section{EKLER}

\section{Sayıları Okuma Yazma Formu}

S.1) 213786549 sayısının okunuşunu alttaki kutunun içine yazı ile yazınız.

S.2)Sekiz yüz üç milyon on yedi bin kırk dokuz sayısını rakamlarla ifade ediniz.

S.3) Așağıdaki sayının okunuşunu yazı ile yazınız.

\begin{tabular}{|l|l|l|l|l|l|l|l|l|}
\hline \multicolumn{2}{|l|}{ Milyonlar Bölüğü } & \multicolumn{3}{|l|}{ Binler Bölüğü } & \multicolumn{3}{|c|}{ Birler Bölüğü } \\
\hline $\begin{array}{l}\text { Yüz } \\
\text { milyonlar }\end{array}$ & $\begin{array}{l}\text { On } \\
\text { milyonlar }\end{array}$ & Milyonlar & $\begin{array}{l}\text { Yüz } \\
\text { binler }\end{array}$ & $\begin{array}{l}\text { On } \\
\text { binler }\end{array}$ & Binler & Yüzler & Onlar & Birler \\
\hline 2 & 6 & 5 & 4 & 3 & 7 & 9 & 0 & 1 \\
\hline
\end{tabular}

\section{S.4) Așağıda basamak değerleri yazılı olan sayıyı rakamlarla yazınız}

\begin{tabular}{|l|l|l|l|l|l|l|l|l|}
\hline \multicolumn{2}{|l|}{ Milyonlar Bölüğü } & \multicolumn{3}{|l|}{ Binler Bölüğü } & \multicolumn{3}{|c|}{ Birler Bölüğü } \\
\hline $\begin{array}{l}\text { Yüz } \\
\text { milyonlar }\end{array}$ & $\begin{array}{l}\text { On } \\
\text { milyonlar }\end{array}$ & Milyonlar & $\begin{array}{l}\text { Yüz } \\
\text { binler }\end{array}$ & $\begin{array}{l}\text { On } \\
\text { binler }\end{array}$ & Binler & Yüzler & Onlar & Birler \\
\hline & & & & & & & & \\
\hline 200000000 & 60000000 & 5000000 & 400000 & 30000 & 7000 & 900 & 80 & 6 \\
\hline
\end{tabular}

S.5) Aşağıdaki sayıyı alttaki kutunun içine yazınız

Sekiz milyon beş bin üç

S.6) 34175869823 sayısının okunuşunu alttaki kutunun içine yazınız

S.7) 800003001005 sayısının okunuşunu alttaki kutunun içine yazınız

S.8) Elli bir milyar on sekiz bin beş sayısını rakamlarla alttaki kutunun içine yazınız

S.9) Düşünebildiğiniz en büyük sayıyı rakamla alttaki kutunun içine yazınız

S.10) Yazdığınız en büyük sayının okunuşunu alttaki kutunun içine yazınız 


\section{Summary}

Purpose and Significance: The first step to improve knowledge of mathematical concepts of students is to use the concept of counting and cardinality. While thinking about some functions of mathematics which are calculation using numbers, reasoning and thinking, the importance of the concept of number and reading and writing them can be understood more easily. Count is an operation performed on objects located in the nature, and the number is the result of this operation. In other words, the counting process and the number is the result. Today, decimal system is widely used when assets and objects are expressed. The concept of place value is defined as the value that the numbers have taken according to the place they are in. The concept of place value is important for many arithmetic operations, such as mental calculation, reading and writing of natural numbers, as well as for other branches of mathematics, especially algebra.

The majority of students have difficulty in establishing relationships between digits, distinguishing between place and digit values, or grouping numbers by place value. In the primary level mathematics program, natural numbers and basic mathematical operations with natural numbers are widely used so students are given the opportunity to acquire knowledge and skills that will form the basis for real life and subsequent education experiences. In the Mathematics Program, students are told that under the learning area of numbers and operations, three learning outcome of natural numbers must be told in a nine-hour time period (teaching the place value, period and digit value up to nine digits). In daily life, it is known that in visual and written media, trillions or quadrillions in expressions are used in various ways (when expressing the investments made in the country). For this purpose the aim of this research is to investigate middle school students' difficulties in reading and writing natural numbers.

Sub problems:

1- What kind of difficulties do the learners have in reading numbers?

2- What kind of difficulties do the learners have in writing numbers?

3- What kind of difficulties do the learners have in reading and writing numbers given in expanded form?

Methodology: This research was conducted with the case study of qualitative research methods. The population of the research is composed of middle school students (6th grade) who are studying at a school in the Eastern Anatolia Region. The sample of the research is composed of 55 students who are studying in two classroom of the 6th grade of a middle school in 2016-2017. In order to identify difficulties in reading and writing natural numbers for middle 
school students, NRWF (Numbers Reading and Writing Form) has been developed by researchers, consisting of 10 open ended questions. Content analysis was used to analyze the data obtained in the research. The consistency of codes was determined by marking the items with "Agreement" or "Disagreement". According to students' answers to the questions, the situation where researchers use the same code is the "Agreement"; and the cases where researchers did not use the same code were accepted as "Disagreement". The reliability of the research was found to be $81 \%$ using the formula "Reliability = Agreement / (Disagreement + Agreement)" which Miles and Huberman (1994) put forward.

Results: In the NRWF, students were asked to write the reading form of 4 given numbers which were expressed in numerical form. Thus, it can be said that nearly half of the students write incorrect in reading form. Difficulties arising from not assigning the digits from right to left (10 students), not being able to read more than six digits (18 students), and after grouping the digits not being able to write the groups according to the digit values (15 students) have been detected.

By the NRWF students were asked to write the numerical form of 4 given numbers which were expressed in reading form. It can be said that nearly half of the students write in numerical form incorrect. This is similar to the previous situation. Difficulties arising from not being able to write more than six digits (18 students), ignoring “ 0 ” numeral while grouping the digits of the number (16 students) and incorrect or incomplete use of zero (12 students) have been detected.

In NRWF, students were given 2 numbers which were expressed in expanded form and students were asked to write those numbers both in numerical form and reading form. The numbers expressed in expanded form were only able to be read correctly by half of the students and if the expanded form were given in word, students would become more successful. Difficulties arising from not being able to specify the place of the digit corresponding to the place value in the number (18 students) and not being able to read or write numbers expressed in expanded form more than six digits (16 students) have been detected.

Discussion and Conclusion: According to the research findings, it was determined that the students had deficiencies in reading and writing the numbers. It has been found that the majority of the difficulties students have in reading and writing numbers are a result of not understanding the place value concept. This result is similar to the results of Vareles and Becker's (1997) research on the place value concept, in which students have had difficulties with the place value concept and have confused the place value with the digit value concept. In the research, it has 
been reached that the students have difficulties with the concept of "grouping" (one, thousand, million, ...), which is accepted as the basis of the place value concept for primary school students. This result is parallel to the results of the studies done by Dinç Artut and Tarım (2006), Kami and Joseph (1988) and Vareles and Becker (1997) on the concept of step value for primary school students.

Recommendations: In the light of research findings and conclusions, the following recommendation can be included:

- Instead of saying abstract examples in number teaching, concrete and different kinds of activities which can be related to daily life should be used.

- Place value and grouping concepts should be emphasized enough in number teaching.

- Knowing the student deficiencies regarding the use of the numeral "0" in the number, rich examples of teaching the number "0" should be included in the number teaching. Activities (i.e. gamification) that can be done in order to overcome the deficiencies of the students in reading and writing the numbers should be investigated. 